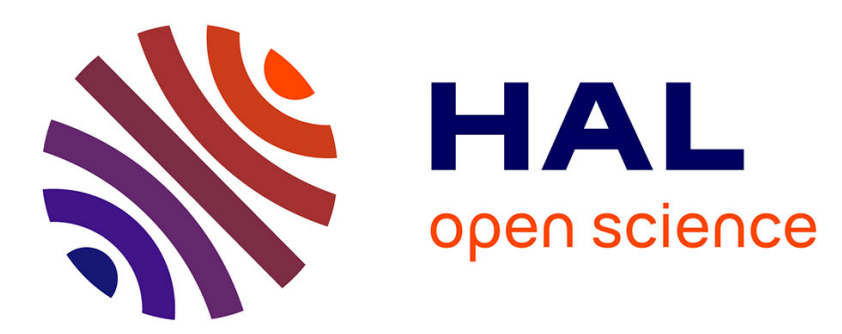

\title{
Martensitic Transformation and Residual Stresses after Thermomechanical Treatment of Heat Treatable Steel 42CrMo4 (SAE 4140)
}

A. Weise, G. Fritsche

\section{- To cite this version:}

A. Weise, G. Fritsche. Martensitic Transformation and Residual Stresses after Thermomechanical Treatment of Heat Treatable Steel 42CrMo4 (SAE 4140). Journal de Physique IV Proceedings, 1996, 06 (C1), pp.C1-265-C1-274. 10.1051/jp4:1996126 . jpa-00254158

\section{HAL Id: jpa-00254158 https://hal.science/jpa-00254158}

Submitted on 1 Jan 1996

HAL is a multi-disciplinary open access archive for the deposit and dissemination of scientific research documents, whether they are published or not. The documents may come from teaching and research institutions in France or abroad, or from public or private research centers.
L'archive ouverte pluridisciplinaire HAL, est destinée au dépôt et à la diffusion de documents scientifiques de niveau recherche, publiés ou non, émanant des établissements d'enseignement et de recherche français ou étrangers, des laboratoires publics ou privés. 


\title{
Martensitic Transformation and Residual Stresses after Thermomechanical Treatment of Heat Treatable Steel 42CrMo4 (SAE 4140)
}

\author{
A. Weise and G. Fritsche \\ Technische Universität Chemnitz-Zwickau, Fakultät für Maschinenbau und Verfahrenstechnik, Professur \\ Werkstoffe des Maschinenbaus, 24300-09107 Chemnitz, Germany
}

\begin{abstract}
The influence of thermomechanical deformation on the residual stresses caused by quenching in bar shaped specimens of heat treatable steel $42 \mathrm{CrMo} 4$ has been investigated using a mechanical method for determining the distribution of residual stresses of the first kind. The results obtained show that the residual stress distribution after quenching is affected by the strengthening and softening of the austenite as a result of deformation and recrystallization and the modified transformation behaviour in martensite stage. An attempt is made to discuss qualitatively the influence of these changes on the generation of residual stresses as compared to results obtained after conventional hardening.
\end{abstract}

\section{INTRODUCTION}

The structure of the material and the residual stresses a component part contains are responsible for its behaviour under certain loading conditions and the distortion in the result of further manufacturing as well. The generation of residual stresses during quenching in heat treatment has been frequently discussed in the literature as a result of interactions between temperature, phase transformations, and strains and stresses [1].

Although widely used in the industrial manufacturing of sheet steels, sections and several forging parts, any systematic investigations concerning the development of residual stresses during thermomechanical treatment has not yet been known. Thermomechanical deformation in the temperature range of stable austenite leads to a strengthening of austenite. Dynamic and/or static recovery and/or recrystallization during and after the deformation step decrease the strengthening effect due to deformation. Thus, austenitic structures with very different mechanical properties can be produced at the beginning of cooling or quenching after the deformation. Additionally, the transformation behaviour of steel is influenced by these processes in that the conditions for nucleation and growth of the product phases are varied. The deformation will be always more or less inhomogeneous and gives rise to internal stresses after the deformation, because of the friction between the tool and the workpiece, the heat generation during forming and the heat transfer into the tool. These internal stresses can be relieved thermally after the deformation process.

To obtain an overview how these processes influence the residual stresses of the first kind after quenching of thermomechanically rolled bar-shaped specimens of heat treatable steel 42CrMo4 (SAE 4140) residual stress distributions were measured mechanically using the layer removal method. The results are compared with those obtained after conventional hardening of two bars of different thickness.

\section{MEASUREMENT OF RESWUAL STRESSES}

An apparatus for measuring residual stresses of the first kind based on the layer removal method has been developed. Like all mechanical techniques for determining residual stresses this method consists of the measurement of macroscopic strains on the specimen, released during the successive removal of stressed layers of material. The residual surface stresses as well as residual stress distributions beneath the surface can be calculated from the measured strains as is shown schematically in Fig. 1. 


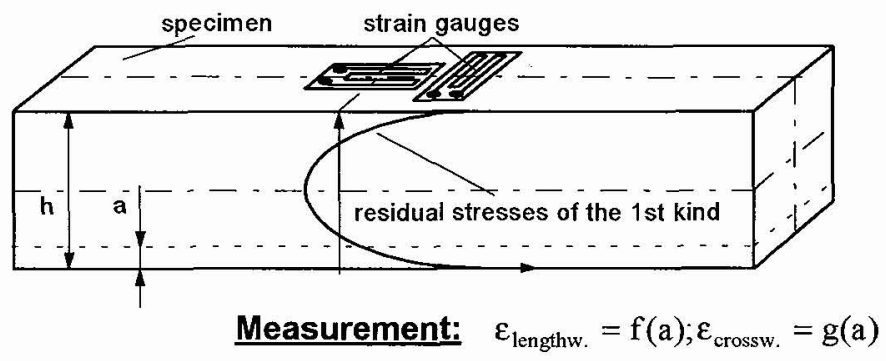

$$
\begin{aligned}
& \varepsilon_{1}=\varepsilon_{\text {lengthw. }}+v \varepsilon_{\text {crossw. }} \\
& \varepsilon_{\mathrm{c}}=\varepsilon_{\text {crossw. }}+v \varepsilon_{\text {lengthw. }} . \\
& \mathrm{E}^{+}=\frac{\mathrm{E}}{1-\mathrm{v}^{2}}
\end{aligned}
$$

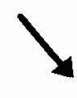

\section{Data smoothing by cubic spline functions}

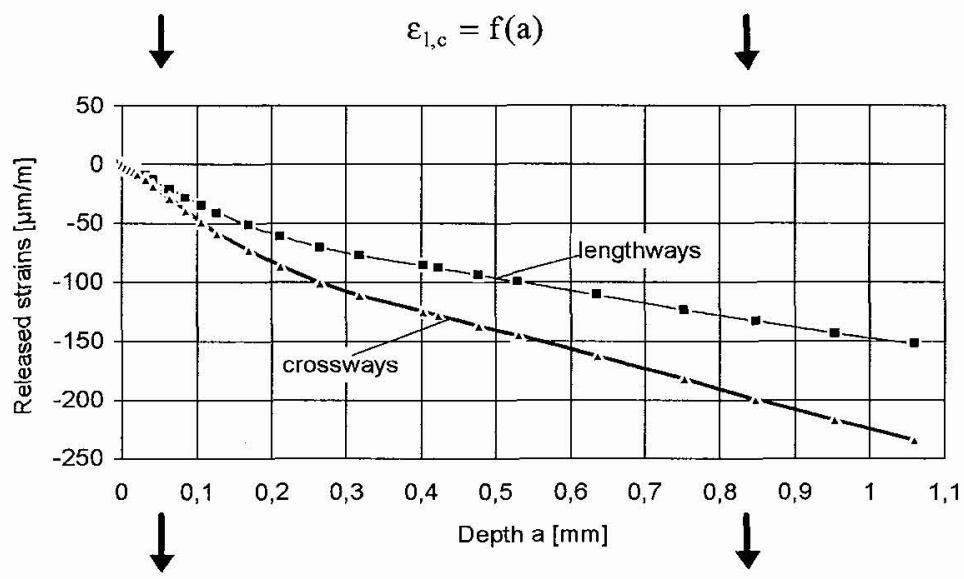

Calculation of residual stresses according to [2] $\sigma_{1, \mathrm{c}}^{\mathrm{RS}}(\mathrm{a})=\mathrm{E}^{+}\left\{-\frac{(\mathrm{h}-\mathrm{a})}{2} \frac{\mathrm{d} \varepsilon_{1, \mathrm{c}}}{\mathrm{da}}(\mathrm{a})-\varepsilon_{1, \mathrm{c}}(\mathrm{a})+3(\mathrm{~h}-\mathrm{a}) \int_{0}^{\mathrm{a}} \frac{\mathrm{d} \varepsilon_{1, \mathrm{c}}}{(\mathrm{h}-\mathrm{a})}\right\}$

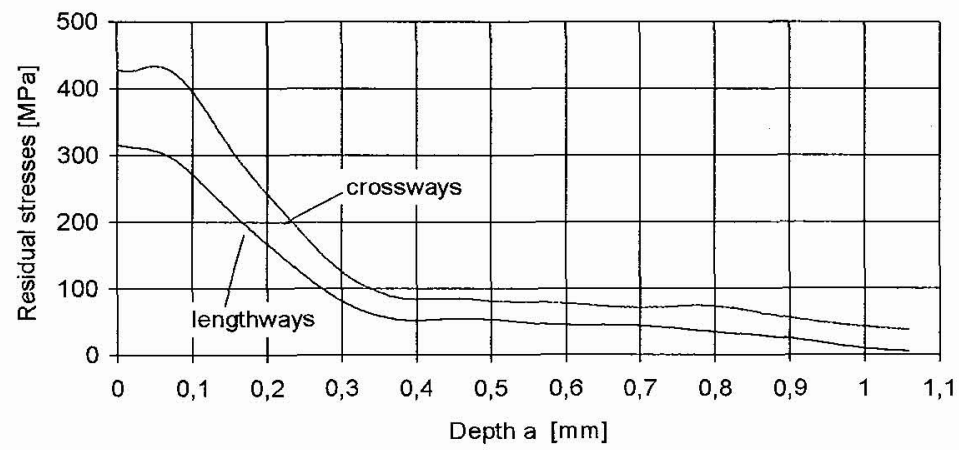

Figure 1: Measurement of residual stress distributions using the layer removal method. 
The measured strains released result mainly from the bending of the specimen with a smaller amount from the alteration of length due to removal of stressed layers. They are registered during the etching by strain gauges, mounted lengthways and crossways on the center of the specimen, opposite to the side from which material is removed. The measured strains released as a function of the removed layer thickness are approximated by smoothing cubic spline functions. In comparision with the spline interpolation and the least square fit as used in [3] the smoothing cubic spline functions have proved to be better for approximating the curves $\varepsilon_{\mathrm{L}, \mathrm{c}}=f(\mathrm{a})$. The residual stress distribution in the removed layer can be calculated from these curves according to [2] in length- and crosswise direction of the specimen.

In order to prevent errors due to plastic deformation or manufacturing stresses the successive removal of material is carried out by electrochemical etching using a $10 \% \mathrm{NaCl}$ water solution at a temperature of $35^{\circ} \mathrm{C}$ and a current density of $0,4 \mathrm{~A} / \mathrm{cm}^{2}$.

\section{PROGRAM OF TREATMENTS}

Fig. 2 shows the program of treatments, the chemical composition of the steel selected and the geometry of the specimens as well. Prior to the treatments the material was reheated at $850^{\circ} \mathrm{C}$ for 15 minutes, subsequently cooled to $675^{\circ} \mathrm{C}$, held for complete transformation in the pearlite stage and cooled down to room temperature in order to produce a uniform initial state with ferritic-pearlitic structure.

The thermomechanical treatment (TMT) consisted of reheating to $900^{\circ} \mathrm{C}$ for 10 minutes, cooling down to $850^{\circ} \mathrm{C}$ and $800^{\circ} \mathrm{C}$, respectively, single pass flat rolling, holding at deformation temperature for 1 and $10 \mathrm{~s}$, respectively and subsequent quenching using a quenching oil or water. For simplification, only a single pass deformation was carried out to simulate the finish rolling step. The austenitic structure after reheating at $900^{\circ} \mathrm{C}$ was suggested to be comparable to that after rough rolling at higher temperatures. As the generation of residual stresses during quenching depends largely upon the size and geometry specimens with different thickness were investigated. The flat rolling of the smaller bars was carried out on a $160 \mathrm{~mm}$ rolling mill stand with an average logarithmic strain of 0.357 and an average strain rate of $5 \mathrm{~s}^{-1}$. The bigger ones were treated as well at the Institut für Metallformung / TU Bergakademie Freiberg using their 360 $\mathrm{mm}$ rolling mill stand.

\begin{tabular}{|l|l|l|l|l|l|l|}
\hline $\mathrm{C}$ & $\mathrm{Si}$ & $\mathrm{Mn}$ & $\mathrm{P}$ & $\mathrm{S}$ & $\mathrm{Cr}$ & $\mathrm{Mo}$ \\
\hline $0,41 \%$ & $0,21 \%$ & $0,7 \%$ & $0,021 \%$ & $0,016 \%$ & $0,96 \%$ & $0,16 \%$ \\
\hline
\end{tabular}

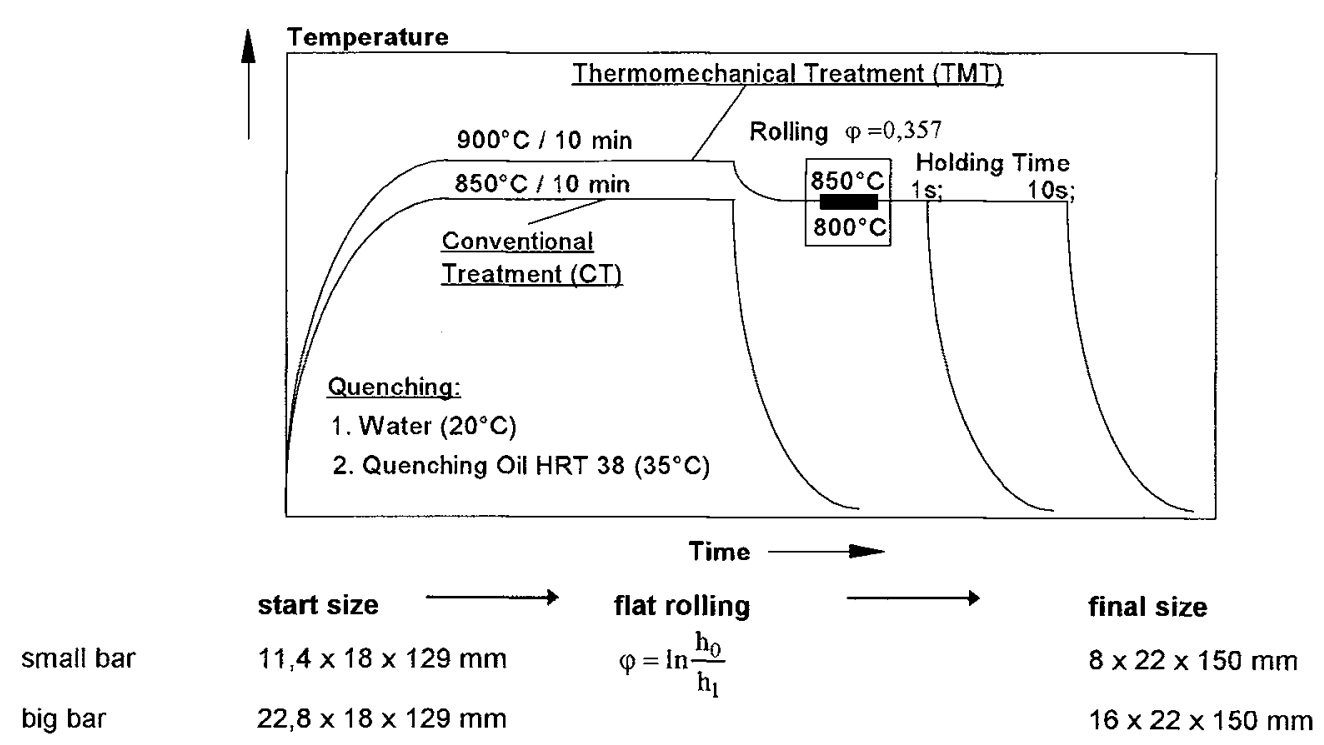

Figure 2: Chemical composition, program of treatments and geometry of the specimens used. 
The holding time at deformation temperature between the end of deformation process and the start of quenching was chosen according to the static softening behaviour of the steel investigated earlier in order to produce austenitic structures with different flow stresses. This will be discussed in detail below.

For comparison, a conventional treatment (CT) without deformation was carried out on specimens of the same sizes as the final sizes of the rolled specimens.

During quenching in oil and water the austenite transforms into martensite, with the exception of quenching the bigger bar in oil, where less than $10 \%$ of austenite transforms into bainite in the core.

\section{RESULTS OF RESIDUAL STRESS ANALYSIS}

Distributions of the lengthways residual stresses are shown for the thinner bars in Figs. 3 and 4 and for the thicker bars in Figs. 5 and 6 , measured after conventional and thermomechanical treatment with rolling temperatures of 850 and $800^{\circ} \mathrm{C}$, respectively. Due to the double thickness a $2 \mathrm{~mm}$ thick layer was removed while measuring the strains relieved on the thicker specimen. The parameters given in the figures are the quenching media and the holding time between the end of rolling process and the start of quenching. Water quenching in the course of conventional treatment led to intercrystalline hardening cracks along the former grain boundaries of austenite. This is why no residual stress measurements were carried out on water quenched undeformed specimens. However, no hardening cracks were observed when the specimen was quenched in water after thermomechanical rolling even if the material was statically recrystallized almost completely during the holding time between the end of rolling process and the start of quenching.

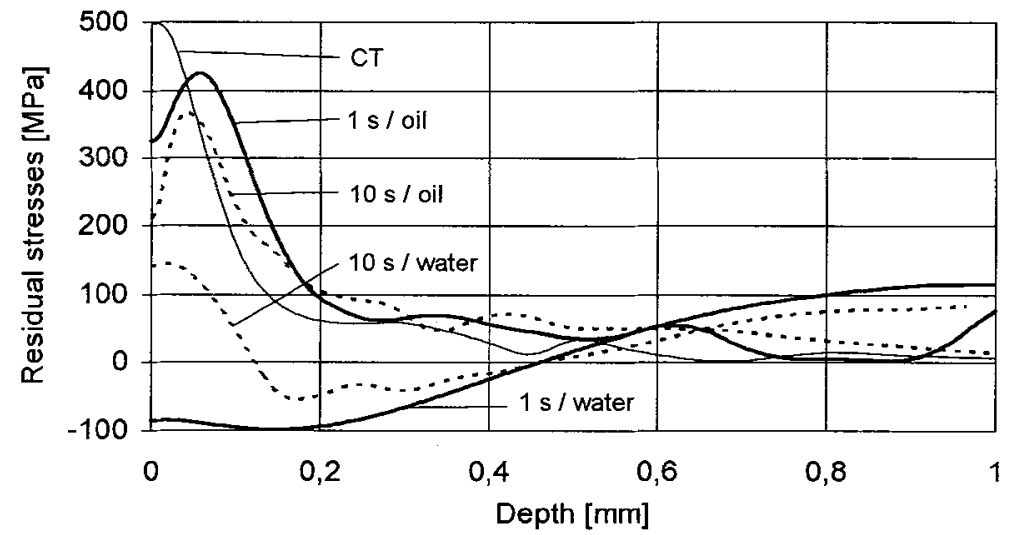

Figure 3: Residual stress distributions after CT and TMT measured on bars $8 \times 22 \times 150 \mathrm{~mm}$ (rolling temperature : $850^{\circ} \mathrm{C}$ ).

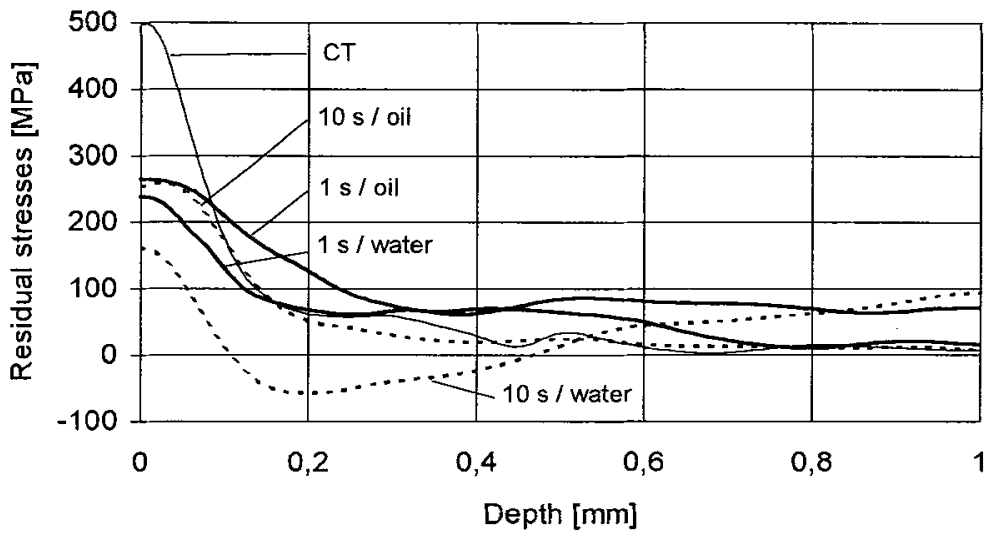

Figure 4: Residual stress distributions after CT and TMT measured on bars $8 \times 22 \times 150 \mathrm{~mm}$ (rolling temperature : $800^{\circ} \mathrm{C}$ ). 
The results obtained can be summarized as follows:

Smaller residual tension stresses were measured in the surface after thermomechanical treatment as compared to the conventional treatment with quenching in oil. Quenching in water led to smaller tension residual stresses than oil quenching or even to compression residual stresses on the surface.

The increase in thickness from 8 to $16 \mathrm{~mm}$ affected the residual stress distribution in that the surface tension residual stresses after oil quenching are lowered. In case of quenching in water, the maximum compression residual stresses below the surface were increased.

Decreasing the rolling temperature led to a lower absolute level of surface residual stresses.

The residual stresses after quenching in water are more intensely affected by the holding time between the end of rolling and the start of quenching than after oil quenching. This will be discussed in detail below.

\section{DISCUSSION}

Residual stresses caused by quenching in heat treatment process are generated as a consequence of interactions between phase composition, temperature field and mechanical reaction of the part to the related volume changes. Thus, a great variety of properties such as geometry, heat transfer coefficient, thermophysical properties, mechanical properties, transformation behaviour in their local dependence on temperature, phase composition and deformation history may influence the residual stress generation in a complex way. This section is aimed at discussing the principal effects of thermomechanical treatment on the flow stress of austenite and the transformation behaviour in the martensite stage in connection with their influ-

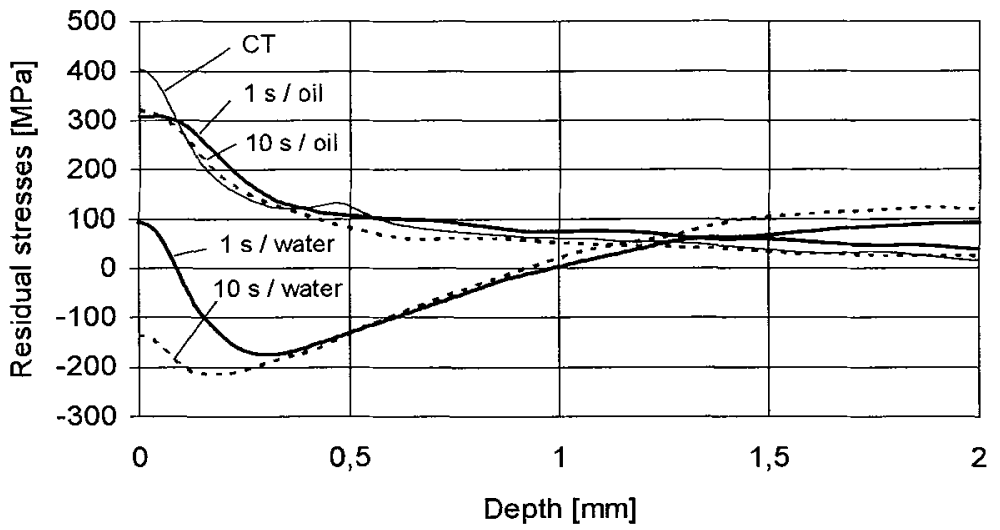

Figure 5: Residual stress distributions after CT and TMT (bars $16 \times 22 \times 150 \mathrm{~mm}$; rolling temperature : $850^{\circ} \mathrm{C}$ )

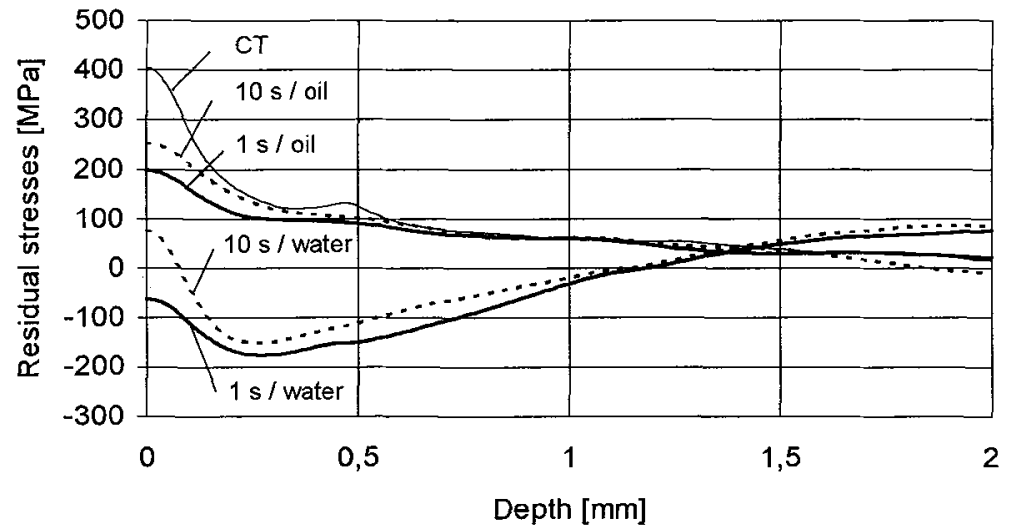

Figure 6: Residual stress distributions after CT and TMT (bars $16 \times 22 \times 150 \mathrm{~mm}$; rolling temperature : $800^{\circ} \mathrm{C}$ ) 
ence on the residual stress generation during quenching as well as the influence of geometry and the quenching media selected.

\subsection{Strengthening and softening of austenite}

During deformation, the flow stress of austenite is enhanced by increasing dislocation density, depending upon local strain, strain rate and temperature. Recrystallization leads to softening of the deformed austenite during or after the deformation process as it largely reduces the dislocation density and it also entails a new formation of the austenite microstructure.

Fig. 7 shows the change of flow stress $\sigma_{\mathrm{f0} .2}$ of austenite as a function of holding time at both rolling temperatures after deformation with a logarithmic strain of $\varphi=0.357$ and a strain rate at $1 \mathrm{~s}^{-1}$. These results were obtained by simulating the course of temperature of Fig. 1 using a deformation dilatometer. Instead of a single pass deformation, double pass deformations by upsetting with varied holding time between the passes were carried out to describe the softening behaviour of the deformed austenite by evaluation of flow curves according to the so-called double impact technique [4]. The specimens used for upsetting were of a cylindrical shape $5 \mathrm{~mm}$ in diameter and $10 \mathrm{~mm}$ in length.

The steep decrease of the flow stress indicated by the lines in Fig. 7 marks the reduction of the dislocation density by static recrystallization. If the specimen deformed at $800^{\circ} \mathrm{C}$ recrystallization starts after an incu-

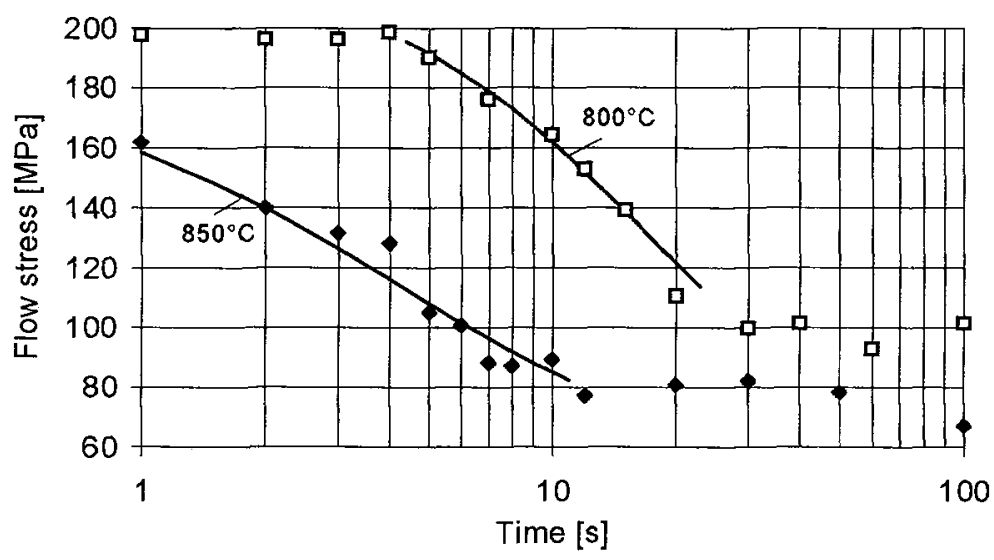

Figure 7: Change of flow stress of deformed austenite as a function of the holding time after deformation.

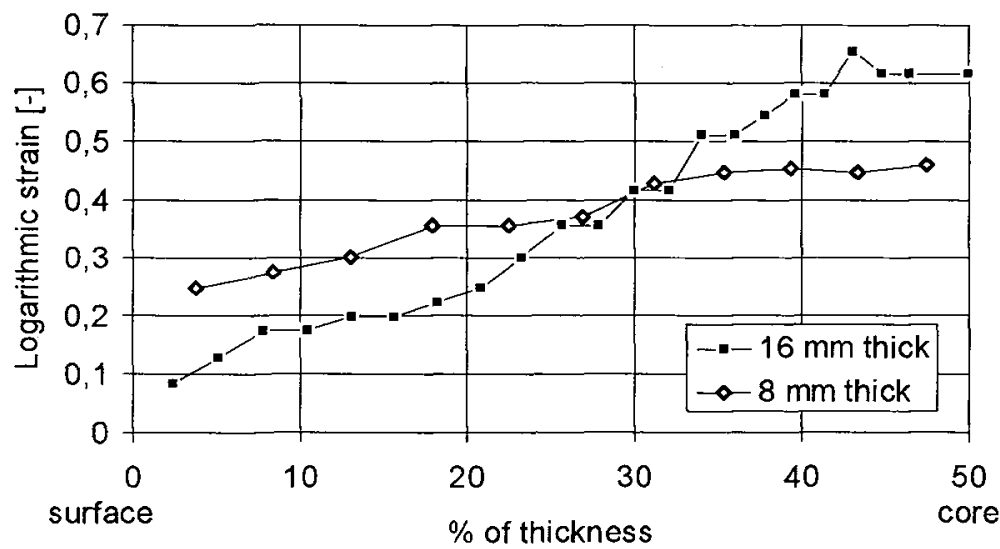

Figure 8: Distribution of the logarithmic strain over half the thickness in the center of the cross section of bars rolled at $850^{\circ} \mathrm{C}$. 
bation time of about 4 to $5 \mathrm{~s}$. No incubation time of static recrystallization is visible in case of deformation at $850^{\circ} \mathrm{C}$ in the time range examined. The deformed austenite is largely softened after $10 \mathrm{~s}$ holding time at $850^{\circ} \mathrm{C}$ and after $30 \mathrm{~s}$ at $800^{\circ} \mathrm{C}$, respectively.

Residual stresses are the result of inhomogeneous plastic deformations during quenching. The higher the yield strength of the material the more thermal and transformation induced macroscopic stresses will be borne more and more elastically in the part to be quenched. Thus, the residual stresses in general will be lowered with increasing yield strength of the material. When compared to conventional hardening with quenching in oil, lower surface residual stresses were observed in all cases after thermomechanical treatment. Due to the higher strengthening of austenite during deformation at $800^{\circ} \mathrm{C}$ and the slower recrystallization the rolled specimen quenched in oil from $800^{\circ} \mathrm{C}$ showed lower tension residual stresses than those quenched from $850^{\circ} \mathrm{C}$ rolling temperature.

However, attention should be given to the fact that deformation is inhomogeneous due to the friction between the specimen and the rolls, due to heat production during deformation and due to the heat transfer from the hot specimen into the cold rolls. The surface region is less strained than the core region of the bars. As a consequence, the strengthening by deformation and the softening by recrystallization cause a yield strength of austenite which differs locally. For illustration, Fig. 8 shows the distribution of the logarithmic strain over half the thickness of the rolled specimen for both geometries. Additionally, inhomogeneous deformation leads to internal stresses after rolling, which are relieved during the holding time after deformation in such a way as to decrease the local yield stress during recrystallization.

\subsection{Influence of geometry and quenching media}

The stresses generated by thermal contraction during quenching depend largely upon the heat transfer coefficient during quenching and the geometry of the specimen. If no phase transformation with volume changes occurs during quenching thermal residual stresses are produced, which are characterized by compression residual stresses in the surface and tension residual stresses in the core. If a phase transformation occurs, the thermal stresses superimpose the stresses resulting from the volume change in transformation. Fig. 9 shows the heat transfer coefficient as a function of surface temperature during quenching determined from temperature measurements in rolled specimens. The heat transfer coefficient varies widely during quenching due to the three stages of stable vapour boiling, nucleate boiling and convection.

When an increase occurs in heat transfer and the thickness of the rolled specimen enhances the surface tension residual stresses are lowered as the thermal stresses during quenching are increasing. The water quenched bars showed generally lower tension residual stresses, or even compression residual stresses on the surface, than the oil quenched bars (see fig 3 to 6). The thicker bars showed the same effect. The influence of thermal stresses are lowered with a decrease in thickness and in the temperature at which quenching starts and with increasing yield strength of the austenite. Thus, tension residual stresses were

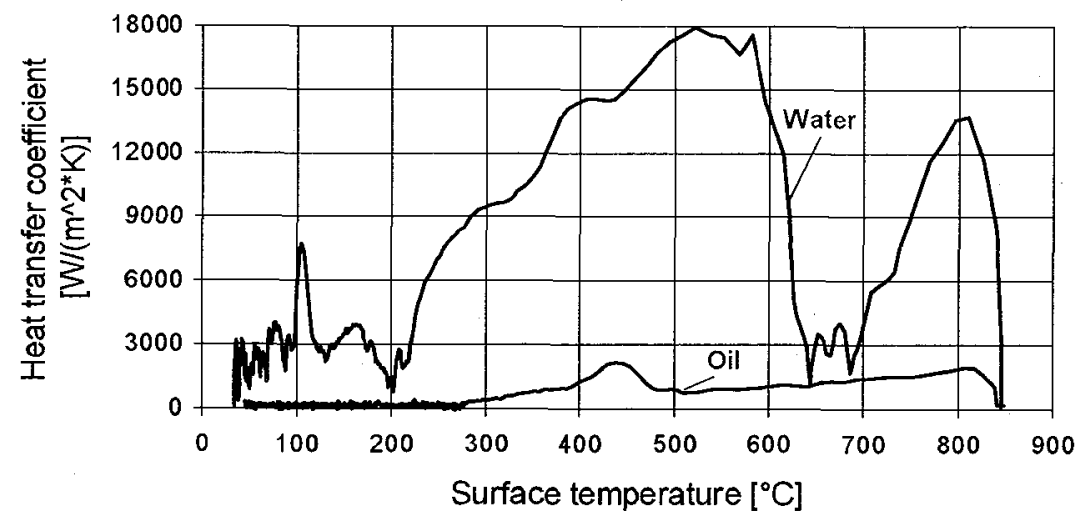

Fig. 9: Heat transfer coefficient in function of the surface temperature of rolled specimen $(8 \times 22 \times 150 \mathrm{~mm}) \mathrm{during}$ quenching. 
produced in the surface of the small bars quenched from $800^{\circ} \mathrm{C}$. Compression residual stresses were produced in the surface, if quenching in water starts at $850^{\circ} \mathrm{C}$ immediately after rolling (Figs. 3 and 4).

\subsection{Martensitic transformation of thermomechanically deformed austenite}

Thermomechanical treatment influences the $\gamma-\alpha$-transformation process due to the increase of the dislocation density, to grain flattening of austenite during deformation and to the grain refinement during recrystallization. Therefore, the conditions for nucleation and growth of the new phases are changed significantly [5]. The influence of the deformation of austenite with subsequent static recrystallization on martensitic transformation was investigated by simulating the temperature course shown in Fig. 2 on a deformation dilatometer. Fig. 10 shows dilatometry curves recorded during quenching with Helium gas of deformed specimens and an undeformed specimen (CT). The parameters given are the deformation temperature and the holding time between the end of deformation and the start of quenching as well as the $\mathbf{M}_{\mathrm{s}}$-temperature determined from these curves. Apart from a small shifting of the martensite start temperature, considerable changes were observed in the dilatations recorded.

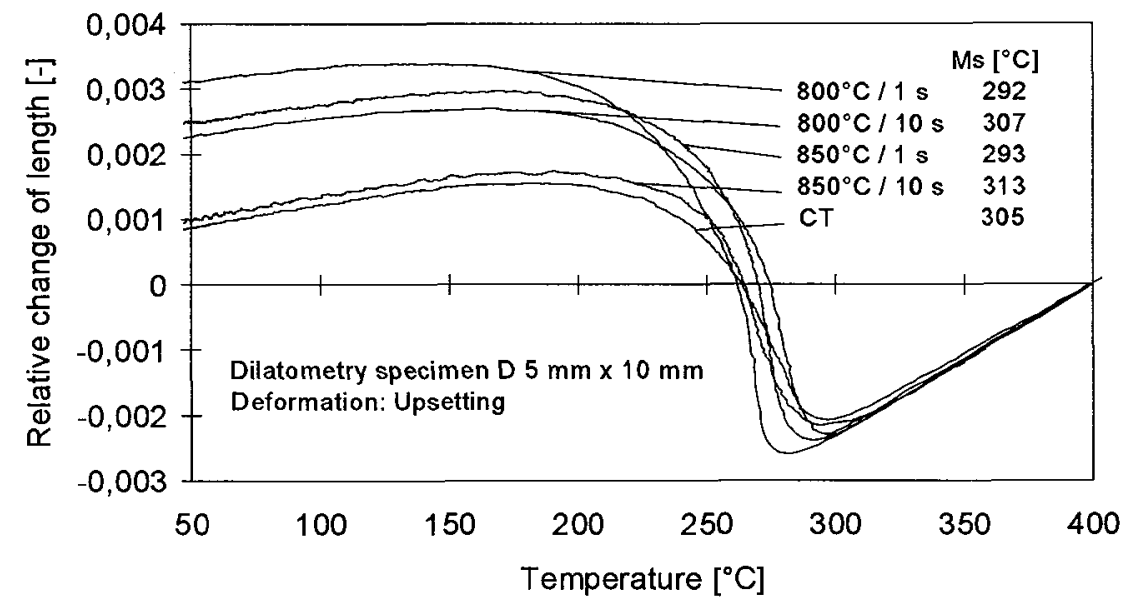

Figure 10: Dilatometry curves after CT and TMT $\left(\varphi_{\mathrm{h}}=0.357 ; \dot{\varphi}=1 \mathrm{~s}^{-1}\right)$.

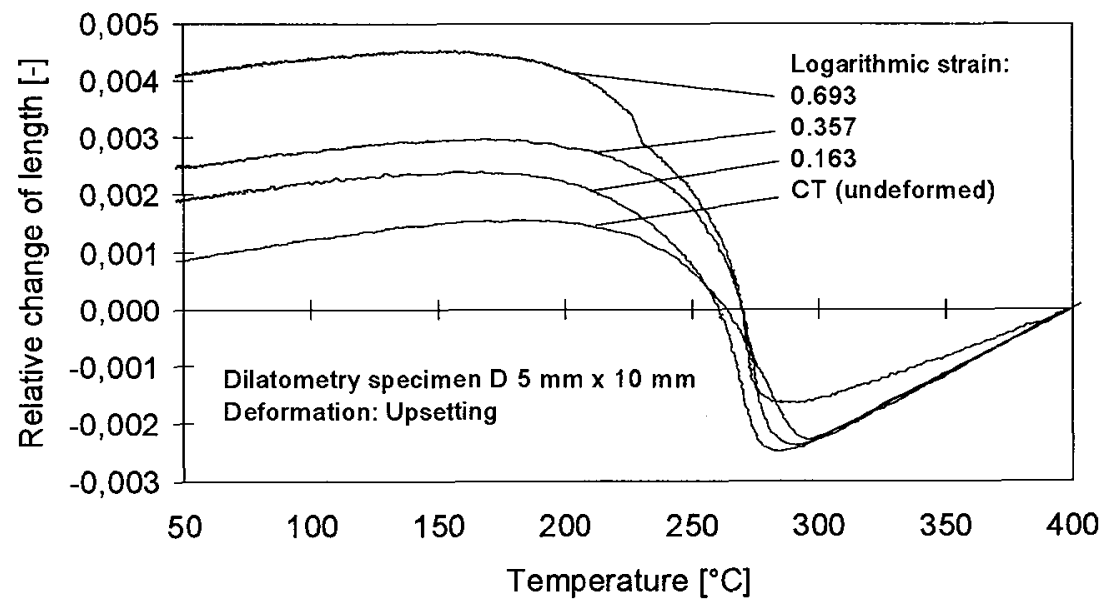

Figure 11: Dilatometry curves after CT and TMT (deformation temperature: $850^{\circ} \mathrm{C} ; \dot{\varphi}=1 \mathrm{~s}^{-1}$ ). 
This effect is similar to that observed for phase transformations under external or internal stresses, known as transformation plasticity [6]. The relative change of length in the direction of deformation seems to depend on whether non-recrystallized austenite or largely recrystallized austenite transforms into martensite as well as on the degree of deformation (Fig. 11). The parameter given in Fig. 11 is the logarithmic strain.

The volume changes accompanying the martensitic transformation are assumed to be approximately constant in all cases regarded. Thus a larger change of length in the direction of deformation of the deformed and non-recrystallized specimens corresponds to a smaller change of length crossways to the direction of deformation. Unlike this, the volume changes accompanying the martensitic transformation of the undeformed specimen (CT) are isotropic. This effect is caused by a texture formation of austenite in connection with a special dislocation arrangement as a result of deformation.

Besides that, [5] reports on the martensitic transformation of a $18 \% \mathrm{Ni}$ maraging steel that laths with only one habit plane were preferentially formed in a deformed austenite grain instead of an activation of all four $\{111\}_{\gamma}$ - habit planes observed in quenched, non-deformed specimens. This restriction of variants of martensite habit plane in the deformed austenite may be closely related to the preferential martensite formation on the most active slip plane.

The selection of variants and the texture of austenite may lead to an anisotrope volume change during martensitic transformation, since the invariant shear deformations forming martensite occur in preferred directions due to the orientation of the activated habit planes.

Fig. 12 shows pole figures of the $\{111\}_{\gamma}$-planes of an austenitic steel X8CrNiTil8.10 in comparison to the $\{110\}_{\alpha}$-planes of martensite of the $42 \mathrm{CrMo} 4$ determined at the center cross sections of deformed dilatometry specimens. The $42 \mathrm{CrMo} 4$ was deformed by upsetting at $800^{\circ} \mathrm{C}$ with a logarithmic strain of 0.693 and a strain rate of $1.0 \mathrm{~s}^{-1}$ after reheating for $10 \mathrm{~min}$ at $900^{\circ} \mathrm{C}$. The austenic steel was deformed as well, but at a temperature at which the flow curve resembled to that of the $42 \mathrm{CrMo} 4$, i. e. at $950^{\circ} \mathrm{C}$ after reheating for $10 \mathrm{~min}$ at $1000^{\circ} \mathrm{C}$. Both specimens were gas quenched using Helium $1 \mathrm{~s}$ after the end of deformation. The $\{111\}_{\gamma}$ - pole figure of the austenitic steel corresponds well to the $\{110\}_{\alpha}$-pole figure of the $42 \mathrm{CrMo} 4$ in accordance with the Kurdjumov-Sachs orientation relationship. Beside this, it was found that the texture of the martensite of the $42 \mathrm{CrMo} 4$ after thermomechanical treatment contains a cube component, which disappears from the $\{200\}_{\alpha}$ - pole figures with progressing static recrystallization of the deformed austenite.

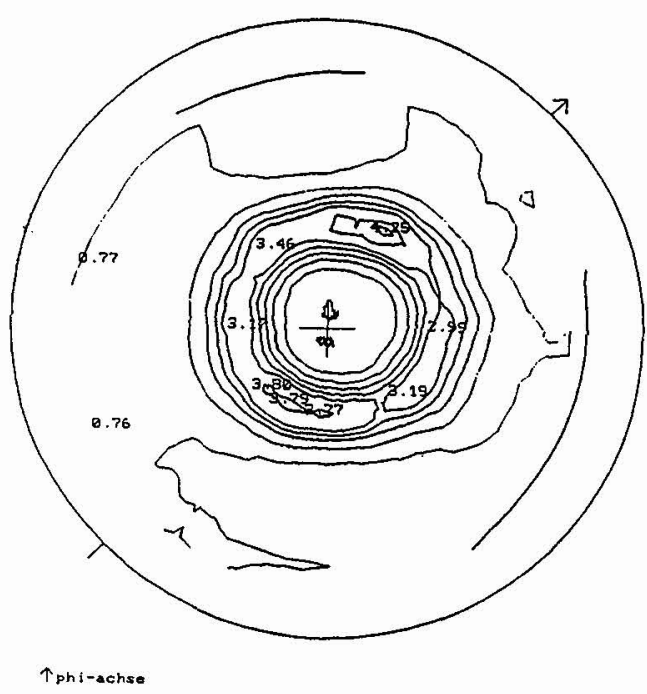

a: X8CrNiTil $8.10\{111\}_{\gamma}$ - Austenite

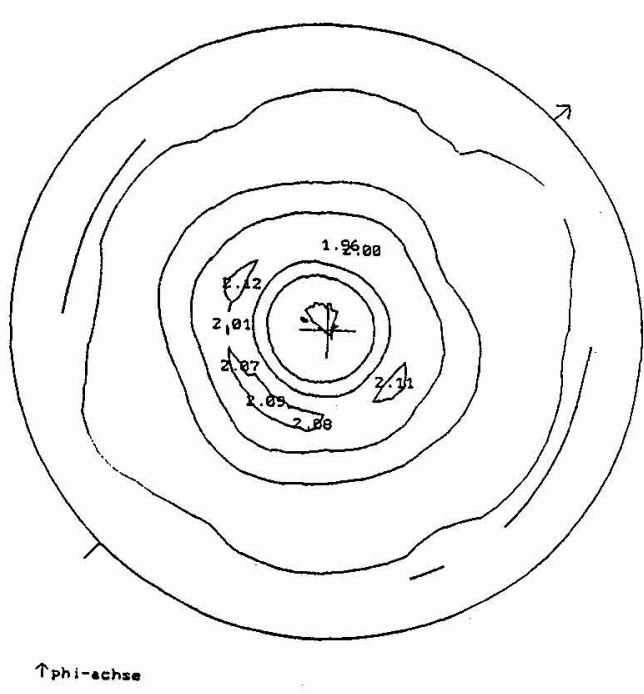

b: $42 \mathrm{CrMo} 4\{110\}_{\alpha}$ - Martensite

Figure 12: Pole figures of $a ;\{111\}_{\gamma}$-planes of the austenitic X8CrNiTi18.10 steel and of $b ;\{110\}_{\alpha}$-planes of the martensite of the 42 CrMo 4 of deformed and quenched dilatometry specimen. 
The anisotropy of volume change during martensitic transformation must influence the generation of residual stresses. It depends on the local strain in the flat rolled specimen and on the local fraction of static recrystallization. As the core of the rolled bars is deformed more intensely than the surface region the anisotropy of volume change is larger than in the surface region. Due to the larger strain, static recrystallization in the core is accelerated as compared to that of the surface. The lengthways residual stress distributions showed in Figs. 5 to 6 seem to reflect this effect especially in the case of water quenching. However, it is difficult to separate the influence of anisotrope volume change from the other effects on the residual stress generation due to the influence of variable austenite yield strength after deformation and recrystallization on thermal stresses. Quenching from $850^{\circ} \mathrm{C} 10 \mathrm{~s}$ after the end of the rolling process led to compression stresses in the surface, indicating that the effect of thermal stresses predominated the effect of transformation stresses during quenching. This results from the largely recrystallized austenite with lower yield strengh and largely isotropic volume change during martensitic transformation. If quenched $1 \mathrm{~s}$ after rolling the fraction recrystallized in the core is higher than in the surface region due to the higher strain in the core and the heat produced during deformation. Thus, the volume changes during martensitic transformation in the surface may be less isotropic than in the core. The change of length in the direction of deformation is larger than crossways to the deformation direction, i. e. a smaller length change is expected in longitudinal direction of the bar than in direction of the thickness. The change of length in longitudinal direction may be larger than in the surface due to more isotrope volume change during martensitic transformation in the core. Thus, tension residual stresses in the surface are generated. The residual stresses obtained after quenching in water from $800^{\circ} \mathrm{C}$ (see Fig. 6) seem to contradict to that as quenching $10 \mathrm{~s}$ after rolling led to a similar residual stress distribution as quenching from $850^{\circ} \mathrm{C} 1 \mathrm{~s}$ after rolling. Recrystallization at $800^{\circ} \mathrm{C}$ is slower than at $850^{\circ} \mathrm{C}$ (see Fig. 7) so the fraction recrystallized over the cross section might be comparable to that after $1 \mathrm{~s}$ at $850^{\circ} \mathrm{C}$ and hence a similar situation of anisotrope volume change during transformation is very likely. Compression residual stresses in the surface were obtained after quenching in water $1 \mathrm{~s}$ after rolling from $800^{\circ} \mathrm{C}$ rolling temperature. Both the surface and core region are largely unrecrystallized. The volume change is more anisotropic than in the surface due to the higher strain in the core, $i$. e. a smaller change of length during martensitic transformation is expected lengthways in the core than in the surface. This may explain the compression residual stresses observed in the surface.

\section{CONCLUSION}

The residual stresses in thermomechanically treated and quenched bars of $42 \mathrm{CrMo} 4$ steel are found to be influenced by the strengthening and softening of the deformed austenite and its modified martensitic transformation with anisotropic volume change. An attempt was undertaken to qualitatively discuss the influence of these effects on residual stress generation during quenching. However, a better understanding of these complicated interacting processes requires FEM calculations of the forming and quenching processes involving a mathematical description of recrystallization and martensitic transformation with anisotropic volume change since the real mechanical response cannot be described correctly by the simplified qualitative considerations discussed above.

\section{Acknowledgements}

Financial support by the Deutsche Forschungsgemeinschaft (DFG) as well as technical support and useful discussions by Prof. W. Lehnert et al. (TU Bergakademie Freiberg) are gratefully acknowledged.

\section{References}

[1] Kloos, K.-H. and Kaiser, B., Härterei-Techn. Mitt. 45(1990) 356-366.

[2] König, G. and Dannenberg, R., VDI-Berichte Nr. 882 (1991), 325-334.

[3] Lippmann, S.; Weise A. and Thieme, U., Härterei-Techn. Mitt. 50(1995), 20-26

[4] Pawelski, O., Z. Metallkunde 68(1977), 79-89

[5] Kaspar, R.; Lotter, U. and Biegus, Chr., Steel research 65(1994), 242-247

[6] Fischer, F.D., Acta metall. mater. 38(1990), 1535-1546 